\title{
Potassium hydroxide activation of activated carbon: a commentary
}

\author{
Tang Shu Hui ${ }^{1,2}$ and Muhammad Abbas Ahmad Zaini, ${ }^{1,2,}$ \\ ${ }^{1}$ Centre of Lipids Engineering \& Applied Research (CLEAR), Ibnu Sina Institute for Scientific \& Industrial Research (ISI-SIR), \\ Universiti Teknologi Malaysia, 81310 UTM Johor Bahru, Malaysia \\ ${ }^{2}$ Faculty of Chemical Engineering, Universiti Teknologi Malaysia, 81310 UTM Johor Bahru, Malaysia
}

Key words: activated carbon, activation, commentary, potassium salts, potassium hydroxide

\section{Article Info}

Received 3 December 2014

Accepted 2 September 2015

*Corresponding Author

E-mail: abbas@cheme.utm.my Tel: +6 (07) 5535552

\section{Open Access}

DOI: http://dx.doi.org/

10.5714/CL.2015.16.4.275

This is an Open Access article distributed under the terms of the Creative Commons Attribution Non-Commercial License (http://creativecommons.org/licenses/ by-nc/3.0/) which permits unrestricted non-commercial use, distribution, and reproduction in any medium, provided the original work is properly cited.

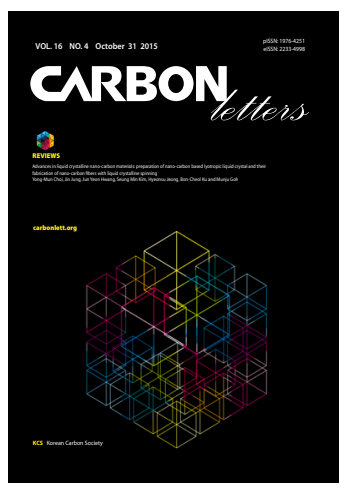

http://carbonlett.org

pISSN: $1976-4251$

elSSN: 2233-4998

Copyright $\odot$ Korean Carbon Society
Over the years, the furnace has been used as a common heating method to manufacture activated carbon. In a furnace, heat is transferred through conduction and convection. The outer surface of the sample is in contact with the generated heat, which slowly diffuses inwards as a result of the thermal gradient between the surface and the core of the material's particles. Another method of heating employs microwave irradiation. Even though it is less energy- and time-consuming, the microwave method has several critical issues with respect to temperature control and thermal runaway, especially in the scaling-up of the microwave heating process [1].

Generally, the activation of a carbonaceous precursor can be performed through physical (steam, air or $\mathrm{CO}_{2}$ ) or chemical activation (activators such as $\mathrm{ZnCl}_{2}, \mathrm{KOH}$, etc.) or a combination of both. The chemical activation is normally preferable over physical activation since it is a faster process with a lower activation temperature. Moreover, the activated carbon produced via chemical activation usually possesses high specific surface area (as determined by the Brunauer-Emmett-Teller, BET method), good pore development and high carbon yield [2,3]. In recent years, potassium salts such as $\mathrm{KOH}$ and $\mathrm{K}_{2} \mathrm{CO}_{3}$ have been widely used in the manufacture of low cost activated carbon. It has been found that activated carbon prepared by $\mathrm{KOH}$ activation is highly microporous when compared to that produced through $\mathrm{ZnCl}_{2}$ or $\mathrm{H}_{3} \mathrm{PO}_{4}$ activation [4-6]. Besides, $\mathrm{KOH}$ also enhances the specific surface area and the formation of $-\mathrm{OH}$ functional groups on the carbon surface [7].

Over the past 5 years, many advantages of $\mathrm{KOH}$ activation have been revealed in the literature [8]. However, the adverse drawbacks of employing $\mathrm{KOH}$ have been overlooked in many of the published studies. In this paper, the preparation of activated carbon by $\mathrm{KOH}$ activation using conventional heating is reviewed and discussed. The limitations and implications of using $\mathrm{KOH}$ in the activation process are highlighted. The selection of appropriate potassium salts for activated carbon preparation is also recommended.

The physical preparation of activated carbon is comprised of two major processes, namely, carbonization and activation of the carbonized sample [4]. Chemical activation is a single step process, as both carbonization and activation occur simultaneously at temperatures ranging between $400^{\circ} \mathrm{C}$ and $700^{\circ} \mathrm{C}$, which is lower than that of physical activation [9]. However, in some cases, additional carbonization or a pre-carbonization step is performed to produce char prior to chemical impregnation and activation [5,4,10-13]. Thus, potassium hydroxide activation can be achieved through either direct chemical activation or char-impregnated chemical activation.

In direct chemical activation, a selected carbonaceous precursor is first dried overnight to remove moisture and then chemically treated at a desired impregnation ratio (weight of $\mathrm{KOH}$ over weight of precursor). The impregnated solid is then heated in a furnace at a specified temperature and time. Carbonization of the precursor is often omitted when the impregnated solid is already suitable for activation.

Table 1 exhibits recently developed activated carbon preparation methods using various precursors and $\mathrm{KOH}$ activation with conventional heating. From Table 1, it can be seen that 
char-impregnated chemical activation is more favourable in the manufacture of activated carbon as compared to direct chemical activation. Pre-carbonization, executed in some studies [12,14], produces some advantages in the textural properties of the activated carbon, although $\mathrm{KOH}$ is a strong base which supports single step activation.

According to Zaini and Kamaruddin [1], the need for precarbonization is determined by the chemical nature of the raw material and the activators used. A starting material which undergoes pre-carbonization (in air or $\mathrm{N}_{2}$ ) could offer larger specific surface area and some initial pore development. As a result, $\mathrm{KOH}$ molecules can easily come into contact with the outer surface of the char. Moreover, the organic substances are converted into rich carbon structure which allows the material to be subjected to more $\mathrm{KOH}$ activation. In another words, the produced char is more susceptible to chemical reaction with $\mathrm{KOH}$, which consequently leads to the formation of a higher degree of mesopores and micropores. Nevertheless, due to insufficient current information, a distinctive contrast between direct chemical activation and charimpregnated chemical activation is deferred.

From Table 1, it is generally found that an activation temperature above $800^{\circ} \mathrm{C}$ and an activation time of more than $30 \mathrm{~min}$ will produce activated carbon with a specific surface area greater than $900 \mathrm{~m}^{2} / \mathrm{g}[6,10-12,15,16]$. However, some studies have revealed a lower product yield of $17 \%$ to $31 \%$ when a temperature above $800^{\circ} \mathrm{C}$ was used $[6,12,17]$. In other words, higher activation temperature and longer retention time could promote the further development of pores, which consequently leads to a greater surface area of up to $2696 \mathrm{~m}^{2} / \mathrm{g}$, and at the same time suffers a lower carbon yield [12]. The pyrolysis with $\mathrm{KOH}$ reduces the amount of carbon due to the intercalation of potassium ions into the carbon matrix, which accelerates the carbon liberation. In addition, further increase in the activation temperature and time may result in both lower surface area and carbon yield, as the micropores collapse to form mesopores and eventually macropores [5].

$\mathrm{Li}$ et al. [18] stated that $\mathrm{KOH}$ activation of carbon-rich kraft lignin produces activated carbon with the superior surface area of $2763 \mathrm{~m}^{2} / \mathrm{g}$. Muniandy et al. [12] also showed that rice husk with $27 \%$ carbon content ends up with activated carbon with a similar surface area of $2696 \mathrm{~m}^{2} / \mathrm{g}$. Thus, it can be said that the carbon content of the precursor may not necessarily affect the pore development of the resulting activated carbon. However, a carbon-rich precursor is generally a potential candidate for activated carbon.

At present, many studies have focused on furnace improvement for the mass production of activated carbon. Most of the chemically treated commercial activated carbons are being synthesized by the conventional heating method owing to its simple temperature monitoring technique. Rahman and Bari[19] claimed that the production cost of physical activation of rice husk using a fabricated, high capacity furnace is relatively lower than that of a muffle furnace or horizontal tube furnace, while producing activated carbon with better adsorption capacity.

Despite the fact that microwave heating may have some advantages, like shorter activation time, and produces a resultant activated carbon with high specific surface area and yield, scientists and engineers are repeatedly dissuaded by a lack of in-depth understanding of microwave energy especially in the scaling-up of the heating process for mass activated carbon production.

Potassium hydroxide has been widely used as an activating agent in activated carbon preparation. It is evident that $\mathrm{KOH}$ activation produces activated carbon with a greater specific surface area and good pore development, but the resulting yield is typically low (around 10\%-40\%) as compared to other activators like $\mathrm{ZnCl}_{2}$ and $\mathrm{H}_{3} \mathrm{PO}_{4}$. This is likely due to the development of pores, which accelerates the carbon loss as a result of the intercalation of metallic potassium ions into the carbon network [26]. During carbonization, $\mathrm{KOH}$ acts as a dehydrating agent, to eliminate the presence of water in the precursor, which thereafter would cause the formation of tar that could clog the pores. The carbonization phase is given as:

$$
\text { Dried precursor } \rightarrow \text { Char }+ \text { Tar }+ \text { Gasses }
$$

During the activation process, the following reactions take place $[27,28]$

$$
\begin{aligned}
& \mathrm{C}+2 \mathrm{KOH} \rightarrow 2 \mathrm{~K}+\mathrm{H}_{2}+\mathrm{CO}_{2} \\
& \mathrm{C}+2 \mathrm{KOH} \rightarrow 2 \mathrm{~K}+\mathrm{H}_{2} \mathrm{O}+\mathrm{CO} \\
& \mathrm{CO}_{2}+2 \mathrm{KOH} \rightarrow \mathrm{K}_{2} \mathrm{CO}_{3}+\mathrm{H}_{2} \mathrm{O}
\end{aligned}
$$

Both mesopores and micropores are formed as a result of the intercalation of potassium into the carbon network during the activation. Besides, there is also a possibility for a secondary reaction to occur as follows [28].

$$
\mathrm{H}_{2} \mathrm{O}+\mathrm{C}+2 \mathrm{KOH} \rightarrow \mathrm{K}_{2} \mathrm{CO}_{3}+\mathrm{H}_{2}
$$

Abechi et al. [5] stated that potassium carbonate produced from $\mathrm{KOH}$ activation could avert excessive sample burn-off, and consequently lead to a high product yield and well developed porosity. However, this notion is not scientifically proven and somewhat contradicted by the findings shown in Table 1. According to Khalil et al. [29], the activated carbon yield is lower at activation temperatures $>700^{\circ} \mathrm{C}$ because $\mathrm{KOH}$ may catalyze the oxidation reactions. As a result, the outer surface carbon atoms are oxidized leading to the formation of pores. This is in agreement with the findings by Mestre et al. [30]. The starting material is likely to disintegrate into powder form when activated with alkaline hydroxide owing to the formation of pores as a result of gasification reactions [31]. In another words, activated carbon with low yield but high porosity is elicited at the expense of char burn-off.

Activated carbon is an economical adsorbent with unique textural properties and good adsorption capacity. In traditional applications, microporous activated carbon (pore width $<2$ $\mathrm{nm}$ ) is usually employed. However, the development of highly mesoporous activated carbon $(2 \mathrm{~nm}<$ pore width $<50 \mathrm{~nm})$ has gaining considerable attention due to its wide range of applications.

From Table 1, it is noteworthy that nearly all $\mathrm{KOH}$-activated carbons possess extensive microporosity, and some can reach up to $96 \%$. The grape seed activated carbon is mainly microporous with a surface area of $1222 \mathrm{~m}^{2} / \mathrm{g}$ [6], while the rice husk activated carbon $\left(2696 \mathrm{~m}^{2} / \mathrm{g}\right)$ is mainly mesoporous [12]. The mesoporous 


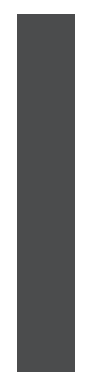

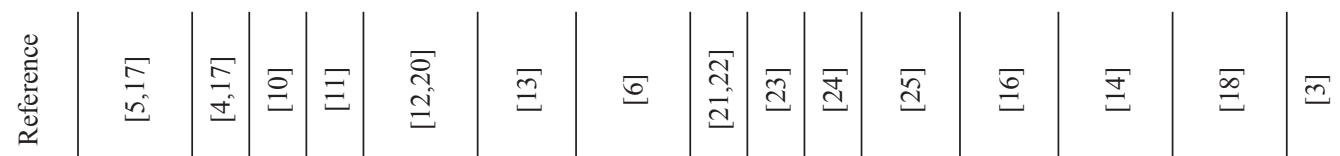

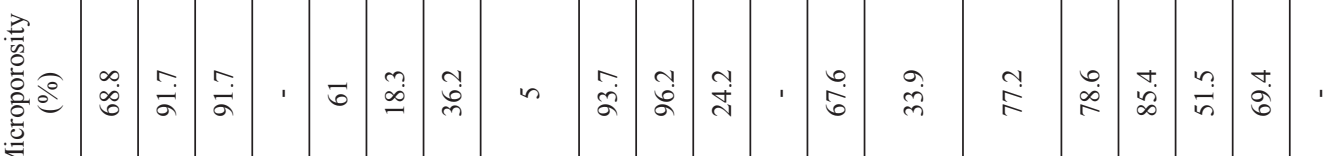

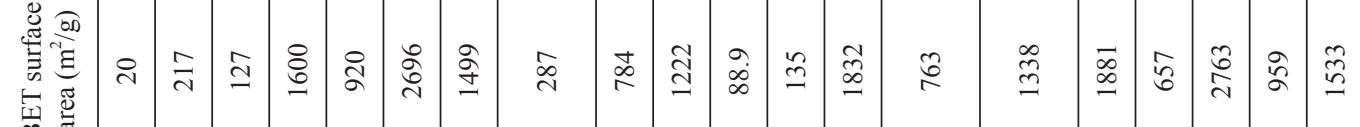

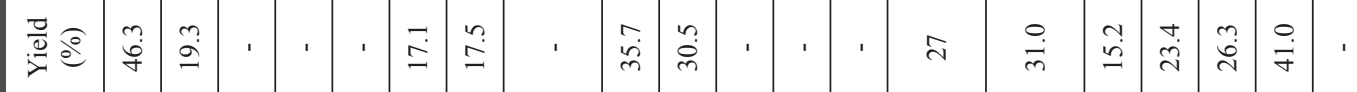

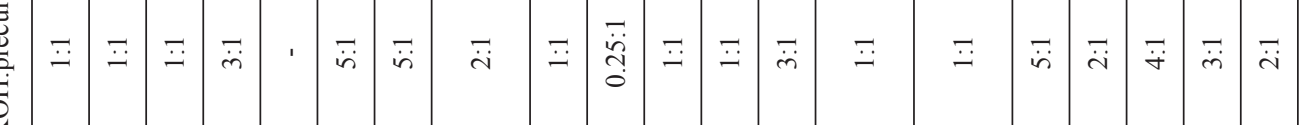




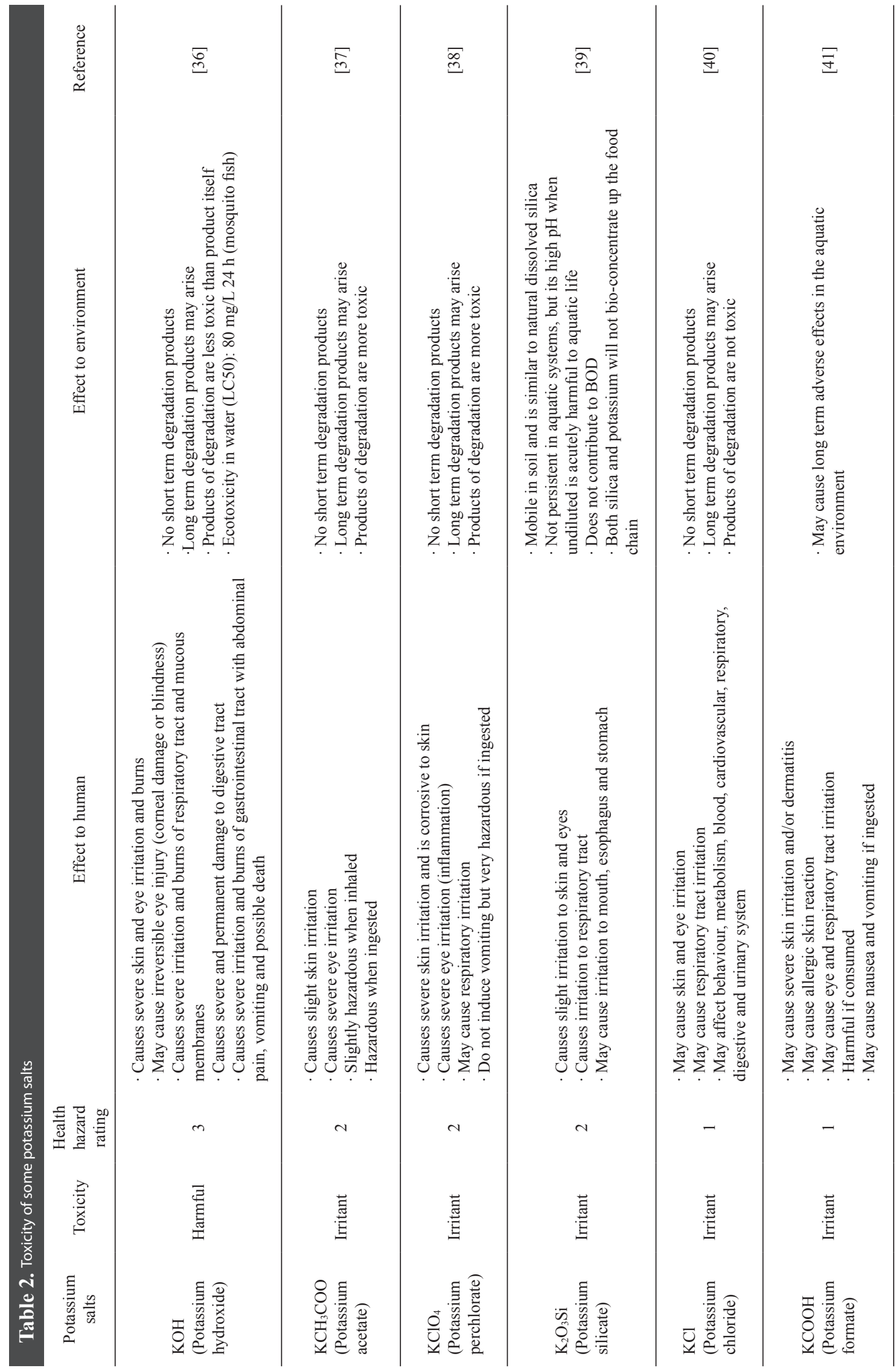


activated carbon produced by $\mathrm{KOH}$ activation is probably due to the manifestation of the lower carbon content of the precursor, and the high impregnation ratio used in the activation.

In air and wastewater treatment, mesoporous carbon material is more suitable for macro-pollutants removal. For example, methylene blue (cationic dye) molecules are more susceptible to lodge on an adsorbent with a pore diameter larger than 1.5 $\mathrm{nm}$ [32]. On the other hand, microporous activated carbon is most widely used, and limited only for the adsorption of micropollutants and heavy metal ions. Because of its small pore diameter $(<2 \mathrm{~nm})$, larger size molecules (macro-pollutants) are therefore prevented from entering the pores.

The mesoporous texture commonly aids in the mass transfer of dye molecules into the bulk of the carbon matrix [33]. Hu and Srinivasan [34] investigated the nature of the porosity and adsorption capacity of different molecular size adsorbates. They reported a higher methylene blue (larger molecular size adsorbate) adsorption of $448 \mathrm{mg} / \mathrm{g}$ by mesoporous coconut shell activated carbon $\left(\mathrm{V}_{\text {mes }} / \mathrm{V}_{\text {total }}=71 \%\right.$; specific surface area $=2191 \mathrm{~m}^{2} / \mathrm{g}$ ) [34]. Similarly, Sun et al. [35] reported that activated carbon with a mesoporous ratio of $61 \%$ and a specific surface area of $1608 \mathrm{~m}^{2} / \mathrm{g}$ can attain the high methylene blue uptake of $1012 \mathrm{mg} / \mathrm{g}$. Therefore, it is sufficient to conclude that mesoporous activated carbon is more efficient for the removal of larger adsorbates.

During the selection of the activating agent for activated carbon preparation, toxicity and its implications for the environment and human health ought to be taken into consideration. In $\mathrm{KOH}$ activation, the activator, while readily impregnated in the precursor, is not completely vaporized, as the activation temperature is generally lower than the boiling point of $\mathrm{KOH}\left(1327^{\circ} \mathrm{C}\right)$. Thus, a considerable fraction of $\mathrm{KOH}$ is highly expected to be released into the aqueous environment when the activated carbon is washed prior to use. To date, almost none of the published studies highlight concerns over the released effluent containing residual $\mathrm{KOH}$ after activation, whether it is in compliance with environmental regulation, or has the potential to be recycled for subsequent activation.

In nature, $\mathrm{KOH}$ is poisonous and toxic as it is a strong base chemical. Table 2 shows that $\mathrm{KOH}$ has a health hazard rating of 3 which indicates that it is harmful and can cause severe damage to human health [36]. If $\mathrm{KOH}$ enters the human body through ingestion, the victim would experience severe and permanent damage to their digestive track, severe irritation and burns of the gastrointestinal tract with abdominal pain and vomiting, and possible death in the worst case scenario [36].

$\mathrm{KOH}$ also creates adverse effects in the environment, especially a water body. $\mathrm{KOH}$ promotes eco-toxicity in water, although its degradation products are less toxic. The growth of mosquito fish takes place when the eco-toxicity (LC50) for $\mathrm{KOH}$ in a water body exceeds $80 \mathrm{mg} / \mathrm{L}$ for $24 \mathrm{~h}$ [36]. One result is that dengue fever can emerge as a public health problem and may even cause death in serious cases, as there is still no cure for this illness. Besides, the ecological balance in a water body may also be affected due to the sudden rise in mosquito fish population, which consequently affects the entire food chain. Thus, an alternative replacement for $\mathrm{KOH}$ as an activator is critically required. Among the family of potassium salts, potassium perchlorate, potassium silicate, potassium chloride and potassium acetate are potential substitutes for $\mathrm{KOH}$ owing to their lower toxicity and reduced impact on the environment.

Potassium chloride $(\mathrm{KCl})$ and potassium acetate $(\mathrm{KCOOH})$ could be regarded as the best substitutes for $\mathrm{KOH}$ because of their low health hazard rating, and they are safer to handle and store. The implications of both $\mathrm{KCl}$ and $\mathrm{KCOOH}$ on the human and environment are almost similar. Ingestion of $\mathrm{KCl}$ may affect human behaviour, metabolism, blood, cardiovascular, respiratory, digestive and urinary system, while that of $\mathrm{KCOOH}$ may trigger nausea and vomiting. The effects of other potassium salts are summarized in Table 2. Nevertheless, further investigations on these alternative activators would be imperative to ensure the effectiveness of activation and also to establish activated carbon with excellent adsorptive properties.

Potassium hydroxide $(\mathrm{KOH})$ has been widely used as an activator for preparing activated carbon. Despite producing well developed porosity and a high specific surface area, the activated carbon yield is usually low. Moreover, the activated carbon produced is highly microporous and this somewhat restricts its applications for the removal of macro-pollutants in air and water. There is also considerable concern over the use of $\mathrm{KOH}$ as an activating agent because of its toxicity and detrimental impacts on humans and the environment. Such drawbacks should be taken into account in the activated carbon preparation. Also, it is of utmost importance to establish alternative activators in the manufacture of excellent activated carbon.

\section{References}

[1] Zaini MAA, Kamaruddin MJ. Critical issues in microwave-assisted activated carbon preparation. J Anal Appl Pyrolysis, 101, 238 (2013). http://dx.doi.org/10.1016/j.jaap.2013.02.003.

[2] Patil BS, Kulkarni KS. Development of high surface area activated carbon from waste material. Int J Adv Eng Res Stud, 1, 109 (2012).

[3] Hirunpraditkoon S, Tunthong N, Ruangchai A, Nuithitikul K. Adsorption capacities of activated carbons prepared from bamboo by KOH activation. World Acad Sci Eng Technol, 5, 591 (2011).

[4] Abechi SE, Gimba CE, Uzairu A, Kagbu JA, Ocholi OJ. Equilibrium adsorption studies of methylene blue onto palm kernel shellbased activated carbon. Int Refereed J Eng Sci, 2, 38 (2013).

[5] Abechi SE, Gimba CE, Uzairu A, Dallatu YA. Preparation and characterization of activated carbon from palm kernel shell by chemical activation. Res J Chem Sci, 3, 54 (2013).

[6] Okman I, Karagöz S, Tay T, Erdem M. Activated carbons from grape seeds by chemical activation with potassium carbonate and potassium hydroxide. Appl Surf Sci, 293, 138 (2014). http://dx.doi. org/10.1016/j.apsusc.2013.12.117.

[7] Viswanathan B, Indra Neel P, Varadarajan TK. Methods of Activation and Specific Applications of Carbon Materials, National Centre for Catalysis Research, Chennai, 1 (2009).

[8] Smith KM, Fowler GD, Pullket S, Graham NJD. Sewage sludgebased adsorbents: a review of their production, properties and use in water treatment applications. Water Res, 43, 2569 (2009). http:// dx.doi.org/10.1016/j.watres.2009.02.038.

[9] Katesa J, Junpiromand S, Tangsathitkulchai C. Effect of carbonization temperature on properties of char and activated carbon from properties of coconut shell. Suranaree J Sci Technol, 20, 269 (2013). 
[10] Song M, Jin B, Xiao R, Yang L, Wu Y, Zhong Z, Huang Y. The comparison of two activation techniques to prepare activated carbon from corn cob. Biomass Bioenergy, 48, 250 (2013). http:// dx.doi.org/10.1016/j.biombioe.2012.11.007.

[11] Hunsom M, Autthanit C. Adsorptive purification of crude glycerol by sewage sludge-derived activated carbon prepared by chemical activation with $\mathrm{H} 3 \mathrm{PO} 4, \mathrm{~K} 2 \mathrm{CO} 3$ and $\mathrm{KOH}$. Chem Eng J, 229, 334 (2013). http://dx.doi.org/10.1016/j.cej.2013.05.120.

[12] Muniandy L, Adam F, Mohamed AR, Ng EP. The synthesis and characterization of high purity mixed microporous/mesoporous activated carbon from rice husk using chemical activation with $\mathrm{NaOH}$ and $\mathrm{KOH}$. Microporous Mesoporous Mater, 197, 316 (2014). http://dx.doi.org/10.1016/j.micromeso.2014.06.020.

[13] Wu C, Song M, Jin B, Wu Y, Huang Y. Effect of biomass addition on the surface and adsorption characterization of carbon-based adsorbents from sewage sludge. J Environ Sci, 25, 405 (2013). http:// dx.doi.org/10.1016/S1001-0742(12)60028-X.

[14] Yu Q, Li M, Ning P, Yi H, Tang X. Preparation and phosphine adsorption of activated carbon prepared from walnut shells by koh chemical activation. Sep Sci Technol, 49, 2366 (2014). http:// dx.doi.org/10.1080/01496395.2014.917326.

[15] Wang L, Zhang Z, Qu Y, Guo Y, Wang Z, Wang X. A novel route for preparation of high-performance porous carbons from hydrochars by $\mathrm{KOH}$ activation. Colloids Surf A Physicochem Eng Asp, 447, 183 (2014). http://dx.doi.org/10.1016/j.colsurfa.2014.01.013.

[16] Adibfar M, Kaghazchi T, Asasian N, Soleimani M. Conversion of poly(ethylene terephthalate) waste into activated carbon: chemical activation and characterization. Chem Eng Technol, 37, 979 (2014). http://dx.doi.org/10.1002/ceat.201200719.

[17] Rugayah AF, Astimar AA, Norzita N. Preparation and characterisation of activated carbon from palm kernel shell by physical activation with steam. J Oil Palm Res, 26, 251 (2014).

[18] Li XF, Xu Q, Fu Y, Guo QX. Preparation and characterization of activated carbon from Kraft lignin via $\mathrm{KOH}$ activation. Environ Prog Sustain Energy, 33, 519 (2014). http://dx.doi.org/10.1002/ ep.11794.

[19] Rahman MM, Bari QH. Development of Furnace for Producing Activated Carbon, International Conference on Mechanical, Industrial and Energy Engineering, Khulna, 1 (2010).

[20] Taha MF, Kiat CF, Shaharun MS, Ramli A. Removal of Ni(II), $\mathrm{Zn}$ (II) and $\mathrm{Pb}$ (II) ions from single metal aqueous solution using activated carbon prepared from rice husk. World Academy of Science, Eng Technol, 5, 1473 (2011).

[21] AL-Othman ZA, Ali R, Naushad M. Hexavalent chromium removal from aqueous medium by activated carbon prepared from peanut shell: adsorption kinetics, equilibrium and thermodynamic studies. Chem Eng J, 184, 238 (2012). http://dx.doi.org/10.1016/j. cej.2012.01.048

[22] Wu M, Guo Q, Fu G. Preparation and characteristics of medicinal activated carbon powders by $\mathrm{CO}_{2}$ activation of peanut shells Powder Technol, 247, 188 (2013). http://dx.doi.org/10.1016/j. powtec.2013.07.013.

[23] Kaçan E, Kütahyali C. Adsorption of strontium from aqueous solution using activated carbon produced from textile sewage sludges. J Anal Appl Pyrolysis, 97, 149 (2012). http://dx.doi. org/10.1016/j.jaap.2012.06.006.

[24] Monsalvo VM, Mohedano AF, Rodriguez JJ. Activated carbons from sewage sludge: application to aqueous-phase adsorption of 4-chlorophenol. Desalination, 277, 377 (2011). http://dx.doi. org/10.1016/j.desal.2011.04.059.

[25] Ncibi MC, Ranguin R, Pintor MJ, Jeanne-Rose V, Sillanpää M, Gaspard S. Preparation and characterization of chemically activated carbons derived from Mediterranean Posidonia oceanica (L.) fibres. J Anal Appl Pyrolysis, 109, 205 (2014). http://dx.doi. org/10.1016/j.jaap.2014.06.010.

[26] Prahas D, Kartika Y, Indraswati N, Ismadji S. Activated carbon from jackfruit peel waste by $\mathrm{H}_{3} \mathrm{PO}_{4}$ chemical activation: pore structure and surface chemistry characterization. Chem Eng J, 140, 32 (2008). http://dx.doi.org/10.1016/j.cej.2007.08.032.

[27] Lillo-Ródenas MA, Cazorla-Amorós D, Linares-Solano A. Understanding chemical reactions between carbons and $\mathrm{NaOH}$ and $\mathrm{KOH}$ : an insight into the chemical activation mechanism. Carbon, 41, 267 (2003). http://dx.doi.org/10.1016/S0008-6223(02)00279-8.

[28] Joseph CG, Zain HFM, Dek SF. Treatment of landfill leachate in Kayu Madang, Sabah: textural and physical characterization (part 1). Malays J Anal Sci, 10, 1 (2006).

[29] Khalil HPSA, Firoozian P, Bakare IO, Akil HM, Noor AM Exploring biomass based carbon black as filler in epoxy composites: flexural and thermal properties. Mater Des, 31, 3419 (2010). http://dx.doi.org/10.1016/j.matdes.2010.01.044.

[30] Mestre AS, Bexiga AS, Proença M, Andrade M, Pinto ML, Matos I, Fonseca IM, Carvalho AP. Activated carbons from sisal waste by chemical activation with $\mathrm{K}_{2} \mathrm{CO}_{3}$ : kinetics of paracetamol and ibuprofen removal from aqueous solution. Bioresour Technol, 102, 8253 (2011). http://dx.doi.org/10.1016/j.biortech.2011.06.024

[31] Marsh H, Rodríguez-Reinoso F. Activated Carbon, Elsevier Science Ltd, Oxford, 87 (2006).

[32] Altenor S, Carene B, Emmanuel E, Lambert J, Ehrhardt JJ, Gaspard S. Adsorption studies of methylene blue and phenol onto vetiver roots activated carbon prepared by chemical activation. J Hazard Mater, 165, 1029 (2009). http://dx.doi.org/10.1016/j. jhazmat.2008.10.133.

[33] Vix-Guterl C, Frackowiak E, Jurewicz K, Friebe M, Parmentier J, Béguin F. Electrochemical energy storage in ordered porous carbon materials. Carbon, 43, 1293 (2005). http://dx.doi.org/10.1016/j. carbon.2004.12.028

[34] Hu Z, Srinivasan MP. Mesoporous high-surface-area activated carbon. Microporous Mesoporous Mater, 43, 267 (2001). http:// dx.doi.org/10.1016/S1387-1811(00)00355-3.

[35] Sun K, Jiang JC, Cui DD. Preparation of activated carbon with highly developed mesoporous structure from Camellia oleifera shell through water vapor gasification and phosphoric acid modification. Biomass Bioenergy, 35, 3643 (2011). http://dx.doi org/10.1016/j.biombioe.2011.05.007.

[36] Potassium Hydroxide MSDS. Available from: http://www. sciencelab.com/msds.php?msdsId=9927230.

[37] Potassium acetate MSDS. Available from: http://www.sciencelab. com/msds.php?msdsId=9927397.

[38] Potassium Perchlorate MSDS. Available from: http://www sciencelab.com/msds.php?msdsId=9924687.

[39] Potassium silicate MSDS. Available from: http://www.pqcorp. com/Portals/1/lit/MSDS/english/AgSil25_Potassium_Silicate_ CA_MSDS2012.pdf

[40] AgSil 25 Potassium Silicate Solution. Available from: http://www sciencelab.com/msds.php?msdsId=9927402.

[41] Potassium Format SDS. Available from: http://www.prochemonline. com/upload/MSDS/2910-1.PotassiumFormate.pdf. 